\title{
ESTRATÉGIAS DE FORMAÇÃO DO PREÇO DE VENDA EM UMA PEQUENA
}

\author{
EMPRESA DE MATERIAIS DE CONSTRUÇÃO
}

\author{
Andressa Carla Palavecini ${ }^{1}$ \\ https://orcid.org/0000-0001-6550-7230 \\ Configurações \\ Flavia Regina Miecoanski² \\ https://orcid.org/0000-0002-2947-6593
}

Recebido em: 2 set. 2020

Aceito em: 29 out. 2020

\begin{abstract}
Como citar este artigo: PALAVECINI, A. C.; MIECOANSKI, F. R. ESTRATÉGIAS DE FORMAÇÃO DO PREÇO DE VENDA EM UMA PEQUENA EMPRESA DE MATERIAIS DE CONSTRUÇÃO: STRATEGIES FOR FORMING THE SALE PRICE IN A SMALL CONSTRUCTION MATERIALS COMPANY. Revista

Visão: Gestão Organizacional, Caçador (SC), Brasil, v. 9, n. 2, p. 138-154, 2020. DOI:

10.33362/visao.v9i2.2377. Disponível em:

https://periodicos.uniarp.edu.br/index.php/visao/article/view/2377.
\end{abstract}

Resumo: Muitos gestores de micro e pequenas empresas utilizam a experiência para tomar decisões, e a falta de informações sobre custos e sobre o mercado geram dificuldades para a formação do preço de venda satisfatória. Nesse sentido, este estudo se propõe a investigar como se dá o processo de formação de preço de venda em uma pequena empresa que atua no comércio varejista de materiais de construção no município de Foz do Iguaçu, Paraná. Trata-se de uma pesquisa qualitativa, descritiva e a coleta dos dados foi por meio de uma entrevista não estruturada com um dos proprietários da empresa. Dentre os principais resultados, tem-se que o gestor tem conhecimento das variáveis fundamentais à formação de preços, mas são necessárias adequações na estimativa de demanda e custos. Sugere-se que a empresa que a empresa utilize séries históricas para previsão de demanda, e realize uma estimativa de custos totais e a devida margem de lucro aplicada para cada produto conforme sua particularidade de mercado. Além disso, verificou-se que a empresa utiliza uma estratégia de diferenciação com posicionamento baseado nas necessidades dos clientes para aumentar sua competitividade frente a concorrência de grandes empresas.

Palavras-Chave: Estratégia. Formação do Preço de venda. Pequena Empresa.

STRATEGIES FOR FORMING THE SALE PRICE IN A SMALL CONSTRUCTION MATERIALS

\footnotetext{
${ }^{1}$ Mestra em Gestão e Desenvolvimento Regional e Graduada em Administração pela Universidade Estadual do Oeste do Paraná- Professora de administração na Universidade Estadual do Oeste do Paraná. E-mail: andressapalavecini@hotmail.com.

2 Doutoranda em Administração na Universidade Estadual de Maringá - UEM. Mestra em Gestão e Desenvolvimento Regional e graduada em Administração pela Universidade Estadual do Oeste do Paraná. E-mail: flaviamiecoanski@gmail.com.
} 


\section{COMPANY}

Abstract: Many managers of micro and small companies use their experience to make decisions, and the lack of information on costs and on the market creates difficulties for the formation of a satisfactory selling price. In this sense, this study aims to investigate how the sale price formation process takes place in a small company that operates in the retail trade of construction materials in the city of Foz do Iguaçu, Paraná. It is a qualitative, descriptive research and the data was collected through an unstructured interview with one of the company owners. Among the main results, it is clear that the manager is aware of the fundamental variables in the formation of prices, but adjustments in the estimate of demand and costs are necessary. It is suggested that the company uses historical series to forecast demand, and make an estimate of total costs and the appropriate profit margin applied for each product according to its particular market. In addition, it was found that the company uses a differentiation strategy with positioning based on customer needs to increase its competitiveness in the face of competition from large companies.

Keywords: Strategy. Sales price formation. Small Business.

\section{INTRODUÇÃO}

As organizações têm sofrido pressões competitivas nunca antes vistas e são forçadas a estar continuamente criando mecanismos para diferenciar-se e impulsionar seus níveis de competitividade (CANEVER et al., 2012). O gestor precisa estar preparado para identificar possíveis oportunidades e ameaças que possam surgir em seu horizonte gerencial e responder de forma assertiva a elas (CALLADO et al., 2014).

No Brasil existem 6,4 milhões de estabelecimentos, desses, $99 \%$ são micro e pequenas empresas (MPE). Elas são responsáveis por 27\% do PIB, 52\% dos empregos com carteira assinada no setor privado (16,1 milhões), 40\% dos salários pagos, sendo 8,9 milhões de micro e pequenas empresas (SEBRAE, 2020).

Em momentos de crise econômica no Brasil, os pequenos negócios demonstraram ser importantes pois, garantiram a ocupação de uma grande parcela da população, por isso, as pequenas empresas têm um papel representativo na economia do país, visto que, podem propiciar oportunidades, impulsionar mercados e gerar empregos mesmo em períodos de recessão. No entanto, o que pode representar um obstáculo a sobrevivência das micro e pequenas empresas é a sua gestão, pois, nestas empresas os sistemas de organização são mais tradicionais, apontando pouca qualificação e especialização dos profissionais envolvidos (TORRES et al., 2019).

Bezerra e Carolli (2015) concordam que muitos gestores utilizam somente seu conhecimento, em detrimento do uso de ferramentas como controle de custos e métodos de formação de preço de vendas. Resende (2013) comentam que essa falta de informações sobre os custos e o sobre o mercado, em micro e pequenas empresas, geram dificuldades na 
definição do preço de venda, sendo comum encontrar situações em que essas empresas adotam estratégias sem critério, gerando prejuízos.

Elaborar um preço que seja coerente é essencial para as organizações, pois é com a venda de produtos e serviços que são obtidos os recursos necessários para a manutenção das suas atividades (RIZZI; ZANIN, 2018). Além disso, o preço é um dos principais determinantes na escolha do que comprar, e os consumidores podem pressionar as empresas a baixarem os preços, ou ainda, podem entender preços baixos como baixa qualidade de um produto ou serviço (KOTLER; KELLER, 2012).

O preço é o elemento do mix de marketing mais simples de ajustar, pois características do produto, canais de distribuição e ações de promoção de vendas demandam mais tempo (KOTLER; KELLER, 2012). Toledo, Proença e Mello Jr. (2006) comentam que as empresas adotam posturas em que o preço é uma reação automática a situações específicas de curto prazo, como alterações de preço na concorrência. Essas ações ocorrem sem planejamento, e quando se trata de ambientes competitivos, é preciso uma abordagem estratégica da formação de preço.

As práticas mais utilizadas para formar preços em pequenas empresas são por meio do acréscimo de uma margem sobre os custos, pesquisa de mercado, e também, por meio de estimativa de preços e indicações dadas pelo fornecedor (BOLZAN, 2015). Nesse sentido, o estudo se propõe a investigar como se dá o processo de formação de preço de venda em uma pequena empresa que atua no comércio varejista de materiais de construção no município de Foz do Iguaçu, Paraná. Paralelamente, sugere um método de formação do preço de venda que pode ser utilizado pela organização.

\section{REFERENCIAL TEÓRICO}

\section{POSICIONAMENTO ESTRATÉGICO}

A maioria dos conceitos de estratégia são definidos como um plano ou curso de ação para o futuro, entretanto, essa definição permite uma fuga do próprio conceito, porque não enfatiza que a estratégia realmente deve ser colocada em prática. A "estratégia é um padrão, isto é uma consistência de comportamento ao longo do tempo". Isso significa que a estratégia de uma organização é como ela efetivamente atua no dia a dia (MINTZBERG; AHLSTRAND; LAMPEL, 2000, p. 17).

Conforme Porter (2004) toda empresa possui uma estratégia competitiva, que pode ser resultado de um processo de planejamento ou que somente evoluiu por meio das atividades realizadas em cada departamento funcional. A essência da estratégia competitiva é realizar atividades de forma diferente dos rivais, visando oferecer uma combinação única de 
valores que permita uma vantagem competitiva (PORTER, 1996).

A vantagem competitiva por meio do posicionamento surgiu na década de $1980 \mathrm{com}$ os trabalhos de Michael Porter (MINTZBERG; AHLSTRAND; LAMPEL, 2000), a partir de uma tipologia de formulação de estratégias competitivas, baseada na compreensão do ambiente no qual determinada empresa compete, pois as regras de competição são influenciadas pela estrutura (RIBEIRO; PISCOPO; MELO, 2006).

Porter (2008) comenta que compreender a estrutura de uma empresa é importante, porque a competição vai muito além da concorrência. Quando se analisa a estrutura de uma empresa, é possível identificar oportunidades que envolvem diferenças nos clientes, fornecedores, produtos substitutos, entre outros.

A estratégia, estrutura e competição, são as condições pelas quais as empresas são criadas, como condições econômicas, institucionais, culturais e jurídicas (MIGLIORINI; FILHO, 2012). A partir desse entendimento de Porter que surgiram as cinco forças competitivas, que são: rivalidade entre as empresas existentes; ameaça de novos entrantes; ameaça de produtos ou serviços substitutos; poder de negociação dos compradores; e poder de negociação dos fornecedores (PORTER, 2004).

Uma estratégia competitiva permite que a empresa assuma um posicionamento em relação a cada uma das cinco forças competitivas (PORTER, 2004). Schneider et al. (2009) comentam que essa posição dominante pode ser criada por meio de três estratégias genéricas, que são liderança em custos, diferenciação e enfoque. As empresas devem escolher uma única estratégia genérica, pois estratégias híbridas, geram desvantagens devido a inconsistência (PORTER, 1998).

A estratégia de liderança em custos está relacionada a empresa fazer com que seu custo seja menor que os concorrentes (CARNEIRO; CAVALCANTI; SILVA, 1997). Conforme Porter (2004) essa posição de custo é um mecanismo de defesa contra os concorrentes, sendo também, uma barreira de entrada em termos de vantagens de custos. Além disso, é uma proteção contra os compradores poderosos que só conseguem baixar o preço até o nível do concorrente com mais eficiência.

Melo e Leone (2015) comentam que a estratégia de diferenciação se resume em oferecer produtos com atributos diferenciados aos da concorrência. Essa estratégia oferece defesa contra a rivalidade dos concorrentes, na medida em que os clientes estão dispostos a pagar por um produto que atenda suas necessidades, ou ainda, como não terão acesso a um produto com as mesmas características na concorrência, o seu poder enquanto compradores diminui. Além disso, a diferenciação permite a aplicação de um preço mais elevado, cobrindo os custos inerentes ao uso dessa estratégia (CARNEIRO; CAVALCANTI; SILVA, 1997).

No caso da estratégia de enfoque, as empresas optam por atender as necessidades de um determinado segmento ou nicho de mercado (HITT, IRELAND, HOSKISSON, 2008). Porter 
(1998) comenta, o enfoque pode manter uma posição de baixo custo ou diferenciação, porém, aplicada a apenas um segmento em específico.

\section{FORMAÇÃO DO PREÇO DE VENDA}

Conforme Bolzan (2015) é por meio dos recursos obtidos com a venda de produtos que a empresa consegue cumprir suas obrigações e se manter no mercado. Além disso, o preço determina a decisão de compra do consumidor, principalmente em mercados onde há um grande número de concorrentes. Isso ocorre, na percepção de Kotler e Keller (2012) porque o consumidor pode definir um preço mínimo para indicar qualidade ou um preço máximo que indique que não compensa realizar a compra.

Determinar as reações do consumidor a diferentes níveis de preço de venda é uma tarefa complexa, e por isso, as empresas enfrentam um dilema durante esse processo. Muitas vezes o preço fixado pela empresa, aquele que traz o melhor resultado interno, pode não ter aceitação total em termos de mercado (VIEIRA, 2008).

Na formação do preço de venda podem ser utilizados diversos métodos e estratégias ligados ao mercado, aos consumidores, concorrência, custo e retorno, por isso, é importante que o gestor conheça cada uma delas. Empresas que formam o preço somente com base em custos e margem podem ter problemas de competitividade (CANEVER et al. 2012).

Os preços dos produtos podem ser formados por meio de três métodos diferenciados, que são: multiplicação de um fator de remarcação sobre os custos, conhecido como mark-up; preços praticados pelo mercado; e por meio de análise de reconhecimento de valor por parte do consumidor (ASSEF, 2011).

Considerando cada método, Assef (2011) comenta que o método baseado em custos e baseado na concorrência são os mais simples e os mais utilizados por pequenas e médias empresas, que podem utilizar só um dos métodos ou ambos. Além disso, sugere que sejam observadas as oportunidades de diferenciação percebidas pelo consumidor, fugindo apenas do modelo baseado em custo ou em concorrência.

O método baseado nos preços praticados pelo mercado, ou seja, com base na concorrência, consiste em observar os preços praticados pelos concorrentes e replicá-los na empresa. Apesar de importante, a concorrência não deve ser o único fator a ser levado em consideração no momento da formação de preços, porque exclui questões estratégicas internas da organização. Em relação ao método baseado no consumidor, o preço é formado com base no valor percebido pelo público alvo, portanto, leva em consideração as características e necessidades do consumidor e o quanto ele está disposto a pagar por esse produto (PINTO; MOURA, 2011).

Apesar de o método de formação de preços considerando somente os custos apesar 
de pouco recomendável em mercados competitivos, conhecer o custos e o mark-up é uma forma de a empresa compreender qual a margem de lucro com em que opera e como isso afeta a informação final sobre os preços (CANEVER et al. 2012). Segundo Kotler e Keller (2012) métodos que não consideram a demanda atual, o valor percebido e a concorrência não levam ao preço ótimo.

A estratégia de preços adequada terá os custos apurados por um método apropriado, análise da concorrência, fatia de mercado que a empresa ocupa, quais os produtos substitutos e qual a percepção de valor do consumidor sobre o produto ou serviço (CANEVER et al. 2012). Por isso, em alguns estudos, os autores citam um método misto, que combina os três métodos anteriores (ZUCCOLOTTO; COLODETI FILHO, 2007; VIEIRA, 2008; CANEVER et al. 2012; RIZZI; ZANIN, 2018).

Conforme Santos (1997) a formação de preço envolve diferentes variáveis que podem ser mais facilmente entendidas quando estruturadas em um modelo que incorpore todos os conceitos e possa ser utilizado como instrumento de gestão. Como são muitas as variáveis, Kotler e Keller (2012) consideram seis etapas para a determinação dos preços, dispostas no Quadro 1, que podem ser utilizadas como instrumento de gestão para a formação do preço de venda.

Quadro 1: Etapas para determinação do preço

\begin{tabular}{|c|c|c|}
\hline ETAPA 1 & $\begin{array}{l}\text { Seleção do objetivo } \\
\text { da determinação de } \\
\text { preços }\end{array}$ & $\begin{array}{l}\text { A empresa precisa decidir onde posicionar a oferta no mercado. } \\
\text { Os objetivos podem ser: } \\
\text { Sobrevivência } \\
\text { Maximização do lucro atual } \\
\text { Maximização da participação de mercado } \\
\text { Desnatamento } \\
\text { Liderança na qualidade do produto }\end{array}$ \\
\hline ETAPA 2 & $\begin{array}{l}\text { Determinação da } \\
\text { demanda }\end{array}$ & $\begin{array}{l}\text { Cada preço tem um impacto diferente na demanda. } \\
\text { Alguns consumidores consideram o preço mais alto um indicador de } \\
\text { um produto melhor, podendo haver crescimento na demanda. } \\
\text { Preços abusivos levam a uma queda na demanda. }\end{array}$ \\
\hline ETAPA 3 & Estimativa de custos & $\begin{array}{l}\text { Os custos determinam o mínimo que deve ser cobrado por um } \\
\text { produto, enquanto a demanda, estabelece o máximo. } \\
\text { A empresa deve cobrar um preço que cubra os custos de produção, } \\
\text { distribuição e venda, e gere um retorno justo. }\end{array}$ \\
\hline ETAPA 4 & $\begin{array}{l}\text { Análise de custos, } \\
\text { preços e ofertas do } \\
\text { concorrente }\end{array}$ & $\begin{array}{l}\text { A empresa deve levar em conta os custos, os preços e as possíveis } \\
\text { reações de preço dos concorrentes. } \\
\text { Deve ser avaliado se a empresa possui características que não são } \\
\text { oferecidas pela concorrência, ou vice versa. }\end{array}$ \\
\hline ETAPA 5 & Seleção de um & Podem ser utilizados seis métodos de formação de preços: \\
\hline
\end{tabular}




\begin{tabular}{|l|l|l|}
\hline & $\begin{array}{l}\text { método de } \\
\text { determinação de } \\
\text { preços }\end{array}$ & $\begin{array}{l}\text { Preço de mark-up } \\
\text { Preço de retorno-alvo } \\
\text { Preço de valor percebido } \\
\text { Preço com base no valor ideal } \\
\text { Preço de mercado } \\
\text { Preço de leilão }\end{array}$ \\
\hline ETAPA 6 & Seleção do preço final & $\begin{array}{l}\text { Ao selecioná-lo, a empresa deve considerar outros fatores como:a } \\
\text { influência de outros elementos do mix de marketing sobre o preço, } \\
\text { suas próprias políticas de preço, o compartilhamento de ganhos e } \\
\text { riscos e o impacto do preço sobre terceiros. }\end{array}$ \\
\hline
\end{tabular}

Fonte: Adaptado de Kotler e Keller (2012).

Kotler e Keller (2012) lembram que as empresas não determinam preços únicos, mas sim, possuem estruturas de determinação de preços que consideram variações geográficas na demanda e custos, exigências de segmentos de mercado, níveis de pedidos, além de práticas como descontos e redução de preços. O Quadro 2 mostra as estratégias de adequação de preços que podem ser utilizadas pelas empresas.

Quadro 2: Estratégias de adequação de preços

\begin{tabular}{|c|c|}
\hline Preço geográfico & $\begin{array}{l}\text { Escambo: É a troca direta de mercadorias entre comprador e vendedor, } \\
\text { sem envolvimento de dinheiro nem de terceiros; }\end{array}$ \\
\hline \multirow{3}{*}{$\begin{array}{l}\text { Determinar preços diferentes } \\
\text { para diferentes clientes, em } \\
\text { diferentes locais e países. }\end{array}$} & $\begin{array}{l}\text { Acordo de remuneração: O vendedor recebe uma porcentagem do } \\
\text { pagamento em dinheiro e o restante em mercadorias. }\end{array}$ \\
\hline & $\begin{array}{l}\text { Acordo de recompra: O vendedor vende uma fábrica, equipamento ou } \\
\text { tecnologia a outro país e concorda em receber pagamento parcial em } \\
\text { produtos fabricados com o equipamento fornecido. }\end{array}$ \\
\hline & $\begin{array}{l}\text { Reciprocidade: O vendedor recebe pagamento total em dinheiro, mas } \\
\text { concorda em despender uma quantia substancial naquele país, em um } \\
\text { período de tempo determinado. }\end{array}$ \\
\hline \multirow{4}{*}{$\begin{array}{l}\text { Preço com desconto } \\
\text { A maioria das empresas } \\
\text { oferece descontos por } \\
\text { pagamento antecipado, } \\
\text { compras de grandes volumes } \\
\text { ou compras fora de temporada. }\end{array}$} & $\begin{array}{l}\text { Descontos: Dedução no preço para compradores que pagam suas contas } \\
\text { em dia ou realizam compras à vista. }\end{array}$ \\
\hline & $\begin{array}{l}\text { Descontos por quantidade: Redução de preço para compradores que } \\
\text { adquirem grandes quantidades da mercadoria. }\end{array}$ \\
\hline & $\begin{array}{l}\text { Descontos comerciais: oferecidos pelo fabricante a membros do canal de } \\
\text { comercialização desde que assumam funções como vender, estocar e } \\
\text { manter registros. }\end{array}$ \\
\hline & $\begin{array}{l}\text { Descontos sazonais: Dedução no preço para compradores que adquirem } \\
\text { mercadorias ou serviços fora de estação. }\end{array}$ \\
\hline Preço promocional & $\begin{array}{l}\text { Preço "isca": Reduzir o preço de marcas conhecidas para estimular um } \\
\text { movimento maior nas lojas. }\end{array}$ \\
\hline $\begin{array}{l}\text { As empresas podem utilizar } \\
\text { diversas técnicas de }\end{array}$ & $\begin{array}{l}\text { Preço de ocasião: As empresas estabelecem preços especiais em certas } \\
\text { épocas para atrair mais clientes. }\end{array}$ \\
\hline
\end{tabular}




\begin{tabular}{|l|l|}
\hline $\begin{array}{l}\text { determinação de preços para } \\
\text { estimular compras }\end{array}$ & $\begin{array}{l}\text { Financiamento a juros baixos: Em vez de reduzir preços, a empresa pode } \\
\text { oferecer ao cliente um financiamento a juros baixos. } \\
\text { Prazos de pagamento mais longos: As empresas oferecem prazos de } \\
\text { parcelamentos mais longos, de modo que as parcelas fiquem mais } \\
\text { acessíveis a capacidade financeira do cliente. } \\
\text { Garantias e contratos de serviço: Oferecer uma garantia ou um contrato } \\
\text { de serviço gratuito ou a um custo baixo. }\end{array}$ \\
\hline $\begin{array}{l}\text { Ocorre quando uma empresa } \\
\text { vende um bem ou serviço por } \\
\text { dois ou mais preços que não } \\
\text { refletem uma diferença } \\
\text { proporcional de custos. }\end{array}$ & $\begin{array}{l}\text { Preço por segmento de cliente: Preços diferentes pelo mesmo bem ou } \\
\text { serviço são cobrados de diferentes grupos de clientes. } \\
\text { breço diferenças por localização: O mesmo produto tem preços diferentes em locais } \\
\text { diferentes, mesmo que o custo seja o mesmo. } \\
\text { Preço por período: Preço varia conforme a temporada, o dia, ou hora. }\end{array}$ \\
\hline
\end{tabular}

Fonte: Adaptado de Kotler e Keller (2012).

Tanto o meio empresarial quanto acadêmico concordam que, um bom gerenciamento de custos e estratégias bem desenvolvidas, são um diferencial competitivo para a organização (MELO; LEONE, 2015). Aplicar métodos de determinação de preço é uma tomada de decisão importante, para isso o gestor pode amparar-se nas estratégias de adequação de preços existentes, mas é preciso considerar as especificidades da organização e dos stakeholders.

\section{MATERIAIS E MÉTODOS}

A pesquisa utiliza-se de uma abordagem qualitativa por buscar informações em profundidade, e conforme Teixeira e Zamberlan (2009) essa abordagem de pesquisa qualitativa requer a interpretação dos fenômenos e a atribuição de significado. Conforme Prodanov e Freitas (2013) esse tipo de pesquisa não utiliza ferramentas estatísticas, pois a prioridade não é numerar ou medir unidades, mas sim, os dados são descritivos e retratam os elementos existentes na realidade estudada.

Quanto aos objetivos, é uma pesquisa descritiva, pois procura descrever as características de determinada população ou fenômeno, busca descobrir a frequência com que um fato ocorre, ou ainda, o estabelecimento de relações entre as variáveis. Os fatos são observados, registrados, analisados, classificados e interpretados, sem interferência do pesquisador (GIL, 2008; PRODANOV; FREITAS, 2013).

A coleta de dados foi realizada a partir de uma entrevista com o gestor da empresa, apoiada por um formulário de entrevista com questões norteadoras elaboradas com base em uma revisão bibliográfica sobre o tema. Para Boni e Quaresma (2005) a entrevista é uma técnica onde o pesquisador busca obter informações de dados objetivos e subjetivos. O investigador 
formula perguntas ao investigado, com o objetivo de obter dados pertinentes ao estudo (GIL, 2008). Essa entrevista foi do tipo não estruturada, que possui perguntas abertas respondidas em uma conversação informal com o entrevistado (PRODANOV; FREITAS, 2013).

O objeto de estudo é uma pequena empresa atuante no comércio varejista de materiais de construção localizada no município de Foz do Iguaçu, Paraná, que iniciou suas atividades no ano de 1994 e conta atualmente com dois sócios, que são casados. Apesar de contar com seis funcionários que atuam nas funções de motoristas, vendedores e serviços gerais, todas as decisões administrativas e operacionais são tomadas por um dos sócios, que atua como gestor da empresa, e foi entrevistado para o fim dessa pesquisa. Essa entrevista foi realizada in loco, ou seja, nas dependências da empresa e foi previamente agendada. O nome da empresa e do entrevistado foram suprimidos visando resguardar as informações fornecidas.

A análise dos resultados, de acordo com Creswell (2009), envolve o processo de analisar e extrair sentido dos dados. Nesta pesquisa a análise dos resultados foi realizada seguindo as etapas conforme sugere este autor: este processo envolve organizar e preparar os dados para análise; ler todos os dados buscando dar um sentido geral as informações e refletir sobre seu sentido; codificar e descrever os cenários e categorias e finalmente interpretar e extrair significado dos dados.

\section{RESULTADOS E ANÁLISE}

Em relação ao processo de formação do preço de venda, Kotler e Keller (2012) comentam que as empresas lidam de diferentes formas, sendo que nas pequenas empresas os preços são determinados pelos proprietários, conforme ocorre na empresa analisada no presente estudo. O gestor afirma não utilizar serviços de assessoria, consultoria ou contabilidade que poderiam auxiliar nessa tarefa.

Considerando as etapas propostas para formulação do preço de venda, a primeira etapa é a seleção do objetivo da determinação de preço, que tem relação com o posicionamento no mercado. Conforme o gestor, o preço é sempre determinado visando atingir a margem de lucro estipulada pela empresa, o que reflete um posicionamento de maximização do lucro atual. Essa estratégia, segundo Kotler e Keller (2012), requer conhecimento da demanda e dos custos, difíceis de estimar.

Outras estratégias não seriam adequadas devido ao porte da empresa, que por ser uma pequena empresa, não conseguiria atuar com uma estratégia de sobrevivência, pois teria que praticar um preço abaixo do mercado, e nem com uma estratégia de máxima participação de mercado, pois não consegue atingir um volume de vendas tão representativo, quanto uma grande empresa consegue.

Conforme Leone (1999) a tomada de decisão em pequenas empresas é baseada na 
experiência, julgamento e intuição do gestor, além disso, nem sempre as informações necessárias estão disponíveis. Essas características se tornam visíveis na segunda etapa de formação de preço, que é a determinação da demanda.

O gestor afirma que prevê a demanda da empresa com base no conhecimento de mercado que possui, que é fruto dos anos de experiência atuando nesse ramo. Não são utilizadas técnicas de previsão de demanda, pois seriam necessárias séries históricas de vendas e a empresa não possui os dados necessários armazenados.

Em relação ao impacto do preço na demanda, o gestor afirma que realiza algumas promoções e descontos personalizados, que serão discutidos nas etapas subsequentes, entretanto, como se trata de uma pequena empresa, essas promoções não conseguem atingir os níveis praticados em grandes empresas. Além disso, o gestor comenta que como se trata de uma empresa que atende um segmento geográfico, que seria o bairro onde está localizada e alguns próximos, os clientes são antigos, compram na empresa há anos, portanto, não percebe grandes alterações na demanda.

No entanto, o que gera um impacto negativo em relação a dificuldade de concorrer com as empresas maiores, quanto a praticar promoções e preços que sejam mais atrativos, seria atrair novos clientes e promover um crescimento na empresa.

Quanto a estimativa de custos, que é a terceira etapa, percebe-se que o gestor também tem dificuldades de acesso a algumas informações que seriam primordiais. Apesar de ter um sistema de informação que poderia fornecer todos os dados necessários para estimar os custos de uma forma mais correta, o gestor utiliza somente para as funções operacionais, como cadastro de clientes e produtos, controle de estoque, vendas, emissão de notas fiscais, etc., e não para tomada de decisão.

Para a determinação dos preços a estimativa de custos envolve somente os custos unitários de cada produto e custos adicionais. O controle feito pelo gestor é muito básico e não envolve as despesas fixas e variáveis que a empresa tem, como energia elétrica, manutenção de veículos, salários, comissões, entre outros. Portanto, o objetivo de maximização do lucro pode não estar sendo atingido em totalidade.

Em relação a quarta etapa que é a análise de custos, preços e ofertas do concorrente, o entrevistado afirmou que o preço praticado pela empresa atende as expectativas dos clientes em comparação a outras empresas do ramo. Esse acompanhamento e monitoramento é feito por meio de conversas informais com outros comerciantes, fornecedores e representantes comerciais, o que vai ao encontro de Bolzan (2015) que comenta que umas das práticas utilizadas por pequenas empresas para formação de preços são indicações dos fornecedores. Além disso, há situações em que os clientes trazem orçamentos realizados em concorrentes para comparar o preço de venda, e o gestor utiliza essas informações para fins de monitoramento. 
O gestor considera importante manter o preço de venda dos produtos de acordo com o praticado no mercado, oferecer descontos e realizar promoções, entretanto, devido ao fato de não conseguir concorrer com as grandes empresas de materiais de construção presentes no município, aposta em um atendimento diferenciado.

É importante comentar sobre o atendimento da empresa nessa etapa da formação de preço, porque para o gestor é um diferencial perante a concorrência. O entrevistado comenta que esse diferencial é uma burocracia mínima, facilidade de negociação quanto a descontos nos preços e prazos mais adaptáveis a situação financeira do cliente, o que nem sempre ocorre em empresas concorrentes.

Conforme Porter (1996) uma empresa pode superar os concorrentes se estabelecer uma diferença que consiga preservar, que pode ser agregar valor aos clientes ou criar valor baseado em custo menor. Quando se entrega um maior valor ao cliente é possível ter preços unitários mais altos, por isso, o gestor investe em uma estratégia de diferenciação quanto ao atendimento da empresa, visando desvincular o sucesso da organização da necessidade de atuar com preços mais competitivos.

Segundo Leone (1999) em pequenas empresas existe uma personalização da gestão na pessoa do proprietário, portanto, ele pode discutir diretamente com os clientes questões diversas visando conhecer seus gostos e necessidades. No caso da empresa estudada, essas características pessoais são visíveis, pois o gestor tem uma proximidade com os clientes, sendo o responsável por negociar diretamente com os mesmos sobre descontos e prazos, situação que é possível, segundo ele, porque são em grande maioria indivíduos que residem no bairro onde a empresa está localizada e bairros próximos e frequentam e compram na empresa há anos.

No entanto, não há muito controle em relação aos descontos e prazos oferecidos e qual o impacto no ciclo operacional de caixa da empresa. O gestor não apresentou dados financeiros da organização, portanto, não foi possível verificar.

Em relação ao método de formação de preços, o entrevistado respondeu que não existe um método formalizado e que nunca sentiu necessidade de fazê-lo por estar satisfeito com a forma como o preço é elaborado. Segundo ele, o preço de venda é formado com base no custo do unitário de cada produto somada uma margem de lucro que é estabelecida conforme o tipo de produto vendido, conforme Tabela 1. 
Tabela 1: Exemplo de demonstração do processo de formação de preço de venda

FORMAÇÃO DO PREÇO DE VENDA
\begin{tabular}{l|l|l|l|l|l}
\hline $\begin{array}{l}\text { Descrição do } \\
\text { produto }\end{array}$ & Quantidade & $\begin{array}{l}\text { Unidade de } \\
\text { medida }\end{array}$ & Custo unitário & $\begin{array}{l}\text { Margem de } \\
\text { lucro }\end{array}$ & Preço de venda \\
\hline AREIA & 1 & $\mathrm{~m}^{3}$ & $\mathrm{R} \$ 30,00$ & $30 \%$ & $\mathrm{R} \$ 39,00$ \\
\hline PEDRA & 1 & $\mathrm{~m}^{3}$ & $\mathrm{R} \$ 45,00$ & $30 \%$ & $\mathrm{R} \$ 58,50$ \\
\hline
\end{tabular}

Fonte: Elaborado pelos autores.

Se houverem custos adicionais a esses produtos, como frete e impostos, o gestor realiza um rateio e atribui esses custos ao custo unitário de cada produto. A Tabela 2 exemplifica um rateio de frete e impostos para os produtos areia e pedra.

Tabela 2: Exemplo de demonstração do processo de rateio dos custos adicionais

\begin{tabular}{l|l|l|l|l}
\hline RATEIO DOS CUSTOS ADICIONAIS \\
\hline Produtos & $\begin{array}{l}\text { Quantidade } \\
\text { comprada }\end{array}$ & Total de produtos & Custo adicional & $\begin{array}{l}\text { Rateio dos custos } \\
\text { adicionais }\end{array}$ \\
\hline Areia & $6 \mathrm{~m}^{3}$ & $12 \mathrm{~m}^{3}$ & $R \$ 30,00$ & $\begin{array}{l}\text { R } \$ 2,50 \text { de custo } \\
\text { adicional para cada } \mathrm{m}^{3}\end{array}$ \\
\hline Pedra & $6 \mathrm{~m}^{3}$ & & \\
\hline
\end{tabular}

Fonte: Elaborado pelos autores.

Ou seja, se o gestor realiza uma compra de $6 \mathrm{~m}^{3}$ de areia e $6 \mathrm{~m}^{3}$ de pedra e ele tem um custos de frete e impostos de $\mathrm{R} \$ 30,00$, esse custo será atribuído de forma igualitária entre cada unidade do produto, portanto, o preço de venda de cada $\mathrm{m}^{3}$ de areia e pedra sofrerá um acréscimo de $\mathrm{R} \$ 2,50$, conforme exemplo na Tabela 3.

Tabela 3: Exemplo de formação do preço de venda com custos adicionais

\section{FORMAÇÃO DO PREÇO DE VENDA COM CUSTOS ADICIONAIS}

\begin{tabular}{l|l|l|l|l|l|l|l}
\hline $\begin{array}{l}\text { Descrição } \\
\text { do produto }\end{array}$ & Quant. & $\begin{array}{l}\text { Unid. de } \\
\text { medida }\end{array}$ & $\begin{array}{l}\text { Custo } \\
\text { unitário }\end{array}$ & $\begin{array}{l}\text { Custo } \\
\text { adicional }\end{array}$ & Custo total & $\begin{array}{l}\text { Margem de } \\
\text { lucro }\end{array}$ & $\begin{array}{l}\text { Preço de } \\
\text { venda }\end{array}$ \\
\hline AREIA & 1 & $\mathrm{~m}^{3}$ & $\mathrm{R} \$ 30,00$ & $\mathrm{R} \$ 2,50$ & $\mathrm{R} \$ 32,50$ & $30 \%$ & $\mathrm{R} \$ 42,25$ \\
\hline PEDRA & 1 & $\mathrm{~m}^{3}$ & $\mathrm{R} \$ 45,00$ & $\mathrm{R} \$ 2,50$ & $\mathrm{R} \$ 47,50$ & $30 \%$ & $\mathrm{R} \$ 61,75$ \\
\hline
\end{tabular}

Fonte: Elaborado pelos autores.

Percebe-se que o método de determinação de preços utilizado pelo gestor é o método 
do mark-up, o qual, consiste basicamente em somar uma margem fixa ao custo unitário do produto para se obter o preço de venda (SARDINHA, 2013). A margem de lucro estipulada pelo gestor é um percentual definido com base na experiência de mercado que o mesmo possui, e não com base em técnicas quantitativas.

O entrevistado comentou que não possui uma margem de lucro padrão, devido a empresa atuar no comércio de diversos produtos que apresentam margens de lucro diferenciadas, alguns produtos permitem uma margem de lucro mais elevada, enquanto outros possuem margens de lucro menores, mas afirma que a margem de lucro estipulada fica em torno de 30\% sobre cada produto. Segundo ele, essa forma de cálculo sempre gerou lucro suficiente para cobrir os gastos da empresa em geral.

O gestor utiliza os componentes de custo, impostos e lucros para a definição do preço de venda dos seus produtos, porém, ele não considera gastos relacionados às despesas fixas e variáveis da empresa, como salários, comissões, energia elétrica, manutenção de veículos, entre outros, o que compromete a lucratividade e afeta o objetivo de determinação de preços, que é a maximização dos lucros.

É importante que ocorra uma revisão dos custos contemplados no processo de formação de preço, porque o gestor pode ter a percepção de que essa margem de lucro cobre todos os custos envolvidos e gera lucratividade, entretanto na prática, isso não ocorre. Isso tem relação também, com a falta de informações disponíveis para a tomada de decisão. Como não foram apresentados os dados financeiros da empresa, não foi possível verificar se houve lucro ou prejuízo nas atividades.

Por fim, a última etapa contempla a seleção do preço final, que envolvem os outros componentes do mix de marketing, bem como, reação da concorrência, além estar de acordo com a política de preços da empresa. Em alguns casos, o preço ainda poderia sofrer ajustes, entretanto, no caso da empresa estudada, percebe-se que o preço final selecionado é aquele proveniente do cálculo do mark-up.

Conforme Toledo, Proença e Mello Jr. (2006) quando o produto faz parte de um mix, como é o caso de produtos vendidos em lojas de materiais de construção, a precificação envolve produtos com custos e demandas inter relacionadas, sendo necessário maximizar o lucro total por meio dos preços praticados.

Considerando essa particularidade, são aplicadas as estratégias de adequação de preços, que envolvem as negociações de prazos e descontos comentadas anteriormente. 0 gestor realiza adequações de preços quando pratica preços promocionais e preços com desconto. No caso dos preços promocionais, a empresa pratica preços de ocasião, fazendo promoções em determinadas épocas do ano, sendo que essas são divulgadas para todos os interessados, e também, oferece prazos de pagamentos mais longos, entretanto, essa é uma prática aplicada conforme o cliente. Quanto ao preço com desconto, são oferecidos descontos 
para pagamento à vista ou em compras em grande quantidade, e também são negociados com cada cliente em específico. Todas as negociações específicas com clientes são feitas pelo gestor.

Percebe-se, portanto, que a empresa atua com uma estratégia de diferenciação, que de acordo com Ribeiro, Piscopo e Mello (2006) diferenciam a oferta da empresa por meio de diferentes dimensões, como por exemplo, o atendimento personalizado, que é praticado pelo gestor da empresa visando competir com os concorrentes.

$\mathrm{Na}$ empresa estudada percebe-se um posicionamento baseado em necessidades, que segundo Porter (1996) ocorre quando um grupo de clientes possuem necessidades diferenciadas, como por exemplo, preços mais baixos, prazos de pagamento mais longos, entre outras, e atividades personalizadas podem atender essas necessidades. Esse posicionamento se aproxima do pensamento de segmentar um segmento de clientes. Dentro do segmento geográfico da empresa, que são os clientes do bairro onde está localizada e bairros próximos, existem clientes com necessidades específicas, que são negociadas pelo proprietário.

\section{CONSIDERAÇÕES FINAIS}

Conclui-se que o objetivo de investigar como se dá o processo de formação do preço de venda em uma pequena empresa que atua no comércio varejista de materiais de construção no município de Foz do Iguaçu, Paraná foi atendido.

Em relação ao método de formação de preços sugerido, percebe-se que o gestor tem entendimento de variáveis como demanda, custos, concorrência, cálculo do preço final, estratégias de adequação de preço que são primordiais para a formação do preço de venda, entretanto, são necessários alguns ajustes, principalmente quanto a estimativa de demanda e custos, visando melhorar esse processo.

Por ser uma pequena empresa, os processos são pouco formalizados, não são aplicadas ferramentas de previsão de demanda e os custos não são estimados de forma totalitária. Além disso, o gestor afirmou que os produtos têm margens de lucro diferenciados, mas não consegue determinar com exatidão as margens para cada produto, utilizando uma margem média de $30 \%$ de lucro para cada item.

Sugere-se, que a empresa utilize séries históricas para previsão de demanda, e realize uma estimativa de custos totais e a correta margem de lucro seja aplicada para cada produto conforme sua particularidade de mercado. Dessa maneira, seria possível praticar uma política de preços que permitisse promoções e descontos de forma a atrair novos clientes e competir com as grandes empresas. Essas ações permitiriam uma maximização dos lucros mais efetiva e uma política de preços mais eficiente.

É de extrema importância a estimativa de custos totais, para que no momento da 
aplicação da técnica de mark-up, além dos custos unitários e adicionais, o gestor considere as despesas fixas e variáveis também. Essa mudança fará com que o objetivo de determinação de preços seja atendido com maior eficiência.

Considerando a dificuldade da empresa em competir em preços, a utilização de uma estratégia de diferenciação por meio da prática de um atendimento personalizado permite que a mesma tenha uma vantagem competitiva no mercado. É importante o reconhecimento das restrições da organização e como contorná-las.

Como limitações, por se tratar de um caso específico de uma pequena empresa, o estudo não permite generalizações. Para pesquisas futuras propõe-se estudar essa mesma organização para verificar se as sugestões propostas obtiveram resultados na estratégia de formação de preço e venda da empresa. E ainda, verificar como se dá a formação de preço e venda em empresas maiores para fins de comparação.

\section{REFERÊNCIAS}

ASSEF, Roberto. Guia prático de formação de preços: aspectos mercadológicos, tributários e financeiros. 4.ed. Rio de Janeiro: Elsevier, 2011.

BEZERRA, Washington Lucena. CAROLI, Adhemar A. de. Análise de custo, volume e lucro: uma perspectiva de controle gerencial nas micro e pequenas empresas. Redeca, v.2, n. 1. jan-jun. p. 45-64, 2015.

BOLZAN, Felipe Augusto. Gestão da formação de preços na indústria de artefatos de cimento - estudo de caso na empresa x. 103 f. Trabalho de conclusão de curso (Graduação em Administração) - Universidade Federal Fronteira Sul, Chapecó, 2015.

BONI, Valdete; QUARESMA Silvia Jurema. Aprendendo a entrevistar: como fazer entrevistas em ciências sociais. Revista Eletrônica dos Pós-Graduandos em Sociologia Política da UFSC, v. 2, p.68-80. 2005.

CALLADO, Antônio André Cunha; CALLADO, Aldo Leonardo Cunha; ALMEIDA, Moisés Araújo. Perspectivas em Gestão \& Conhecimento, João Pessoa, v. 4, n. 1, p. 204-217, jan./jun. 2014.

CANEVER, Felipe Pereira; LUNKES, Rogério João; SCHNORRENBERGER, Darci; GASPARETTO, Valdirene. Formação de preços: um estudo em empresas industriais de Santa Catarina.

Revista de Contabilidade do Mestrado em Ciências Contábeis da UERJ (online), Rio de Janeiro, v. 17, n.2, p. 14 - p. 27, maio/ago., 2012.

CARNEIRO, Jorge Manoel Teixeira; CAVALCANTI, Maria Alice Ferreira Deschamps; SILVA, Jorge Ferreira da. Porter Revisitado: Análise Crítica da Tipologia Estratégica do Mestre. RAC, v.1, n.3, Set./Dez. 1997.

CRESWELL, John. Projeto de pesquisa: métodos qualitativo, quantitativo e misto. 2 ed. Porto Alegre: Artmed, 2009. 
GIL, Antônio Carlos. Métodos e técnicas de pesquisa social. 6 ed. São Paulo: Atlas, 2008.

HITT, Michael A.; IRELAND, R. Duane.; HOSKISSON, Robert. E. Administração estratégica: competitividade e globalização. 2 ed. São Paulo: Cengage Learning, 2008.

MELO, Maurilio Alves de; LEONE, Rodrigo José Guerra. Alinhamento entre as Estratégias Competitivas e a Gestão de Custos: um Estudo em Pequenas Empresas Industriais do Setor de Transformação. BBR - Brazilian Business Review, v. 12, n. 5, Set./Out. 2015.

MIGLIORINI, Sonia Mar dos Santos; DINIZ FILHO, Luís Lopes. O olhar dos empresários do ramo de confecção da região sudoeste do Paraná sobre as fontes de vantagens competitivas encontradas no local para o desenvolvimento do setor. RA'E GA, v. 25, p. 05-37, 2012.

MINTZBERG, Henry; AHLSTRAND, Bruce; LAMPEL, Joseph. Safári de estratégia: um roteiro pela selva do planejamento estratégico. Porto Alegre: Bookman, 2000.

PINTO, Leonardo José Seixas; MOURA, Paola Cristina Cardoso. Formação do preço de venda e estratégias de precificação: o caso da Leader Magazine. In: SEGeT - SIMPÓSIO DE EXCELÊNCIA EM GESTÃO E TECNOLOGIA, 8., 2011. Resende. Anais [...] Resende: AEDB, 2011.

PORTER, Michael E. O que é estratégia? Harvard Business Review, Nov./Dez. 1996.

PORTER, Michael E. Competitive advantage: creating and sustaining superior performance: with a new introduction. New York: Free Press, 1998.

PORTER, Michael E. Estratégia Competitiva: técnicas para análise de indústrias e da concorrência. 2 ed. Rio de Janeiro: Elsevier, 2004.

PORTER, Michael E. The Five Competitive Forces That Shape Strategy. Harvard Business Review, Jan. 2008.

PRODANOV, Cleber Cristiano. FREITAS, Ernani Cesar de. Metodologia do Trabalho Científico: métodos e técnicas de pesquisa e do trabalho acadêmico. 2 ed. Novo Hamburgo: FEEVALE, 2013.

RESENDE, José Flávio Bomtempo (org.) Como elaborar o preço de venda. Belo Horizonte: SEBRAE/MG, 2013.

RIBEIRO, Fernanda C. Ferreira; PISCOPO, Marcos Roberto; MELO, Pedro Lucas de Resende. Liderança em Custos e Segmentação Estratégica: Estudo do Grupo EMS Sigma Pharma. In: SEGeT - SIMPÓSIO DE EXCELÊNCIA EM GESTÃO E TECNOLOGIA, 3., 2006. Resende. Anais [...] Resende: AEDB, 2006.

RIZZI, D.; ZANIN, A. Estratégia de formação de preço de venda/serviço dos empreendedores incubados na Recepeti. Holos, ano 34, v. 02, p. 111-127, 2018.

SANTOS, Roberto Vatan dos. Planejamento do preço de venda. Caderno de Estudos, São Paulo, v.9, n.15, p.60-74, jan./jun., 1997. 
SARDINHA, José Carlos. Formação de preço: uma abordagem prática por meio da análise custo-volume-lucro. São Paulo: Atlas, 2013.

SCHENEIDER, Aline Botelho; CARNEIRO, Marcelo Lopes; SERRA, Fernando A. Ribeiro; FERREIRA, Manuel Portugal. Estratégia competitiva: Michael Porter 30 anos depois Revista de Administração da Universidade Federal de Santa Maria, v. 2, n. 2, maio/ago., 2009.

SEBRAE. Serviço Brasileiro de Apoio às Micro e Pequenas Empresas. Micro e pequenas empresas geram 27\% do PIB do Brasil. 2020. Disponível em:

<https://m.sebrae.com.br/sites/PortalSebrae/ufs/mt/noticias/micro-e-pequenas-empresasgeram-27-do-pib-do-brasil,ad0fc70646467410VgnVCM2000003c74010aRCRD>. Acesso em: 04 ago.2020.

TEIXEIRA, Enise Barth; ZAMBERLAN, Luciano; RASIA, Pedro Carlos. Pesquisa em administração. Ijuí: Ed. Unijui, 2009.

TOLEDO, Geraldo Luciano; PROENÇA, Maria Cristina de Araújo; MELLO JR. Sergio Bandeira de. Política de preços e diferencial competitivo: um estudo de casos múltiplos na indústria de varejo. R.Adm., São Paulo, v.41, n.3, p.324-338, jul./ago./set. 2006

TORRES, Gizelle Villardi; GOUVEIA, Tânia Maria de Oliveira Almeida; KAMLOT, Daniel. Avaliação da qualidade da prestação de serviços de Contabilidade para micro e pequenas empresas do Município do Rio de Janeiro. Revista de Contabilidade do Mestrado em Ciências Contábeis da UERJ (online), Rio de Janeiro, v. 24, n.3, p. 26 - p. 46, set./dez., 2019.

VIEIRA, Eusélia Paveglio. Custos e formação do preço de venda. Unijuí: Ed. Unijuí, 2008.

ZUCCOLOTTO, R.; COLODETI FILHO, E. Gerenciamento de preços em empresas de pequeno porte por meio do custeio variável e do método de Monte Carlo. Enfoque: Reflexão Contábil. Maringá, v. 26, n. 3, p. 39-52, 2007. 